diffused light of the sky caused the photographic reversal of the first image.

Photography thus gives no support to the view that dark lightning has a real physical existence; and Lord Kelvin's letter printed in NATURE of August Io (p. 34I), together with that by Dr. W. J. Lockyer in last week's number, show conclusively that when it is visually observed it is an effect due to fatigue of the retina.

\section{THE RECENT ERUPTION OF ETNA.}

PROF. A. RICCO, Jirector of the Etna Observatory, informs us that on July 19, at 8 a.m., Mount Etna threw out from its central crater an enormous mass of vapour, stones, lapilli, and cinders, which were lifted to a height of several kilonietres, and afterwards covered all the south-east slope of the volcano as far as Zofferana Etnae (altitude $600 \mathrm{~m}$.), where the roads are covered by nearly a centimetre of volcanic ash. A number of stones struck the dome of the Etna Observatory (which is about a kilometre from the central orifice), so that about thirty holes were made in the iron plates, six millimetres in thickness, which cover this dome; five of these holes have a diameter of 30 centimetres, and the stones causing them fell into the observatory containing the refractor. Two stones also pierced the floor, and embedded themselves in the basement ; and one broke three steps of the observing chair. Another pierced the wooden base surrounding the foot of the refractor ; fortunately, this and the other apparatus of the observatory received no damage. Two other stones passed through the roofs of the side-rooms.

Round the observatory there are about fifty holes, caused by the fall and penetration of the stones in the sandy soil.

A heap of straw which was near the stables of the observatory was reduced to ashes, which proves the high temperature of the eruptive materials; moreover, holes were also burnt in the wooden flooring where it had been pierced by stones.

The steam of the eruption condensing in the air gave place to a warm and acid rain in the higher parts of the volcano, and lower down it caused ordinary rain.

The column of steam had by nine o'clock spread itself enormously in the sky nearly over Catania (a distance of $30 \mathrm{~km}$.), and caused a marked darkening. By 9.30 the column had disappeared.

The eruption was accompanied by no perceptible movement of the earth, except a slight shock at the lower end of the Valle del Bove. The instruments at Catania only indicated a very slight oscillation. At the Etna Observatory two seismometers showed horizontal and vertical movements. The eruption was also accompanied by detonations, which were heard very slightly as far as Catania.

On July 25 there occurred a similar eruption, but of less iniportance.

\section{PROFESSOR BUNSEN.}

$\mathrm{O}^{\mathrm{N}}$ Wednesday morning, August 16, the illustrious Heidelberg chemist breathed his last, after a long life wholly devoted to the furtherance of science. In April 188I I communicated to the columns of this journal a sketch of the work of him whose death at the ripe age of eighty-eight all lovers of science now have to deplore. We can only now call attention to the magnitude and extent of that work, and lay on the grave of one of the truest and noblest of men the tribute of our admiration and respect. As expressing the position held by Bunsen amongst the standard-bearers of science, I may, perhaps, be forgiven for quoting the opening sentences of what I wrote eighteen years ago, as I cannot find more approNO. I 557 , VOL. 60] priate words to indicate what all feel who know what his work was.

"The value of a life devoted to original scientific work is measured by the new paths and new fields which such work opens out. In this respect the labours of Robert Wilhelm Bunsen stand second to those of no chemist of his time. Outwardly the existence of such a man, attached, as Bunsen has been from the first, exclusively to his science, seems to glide silently on without causes for excitement or stirring incident. His inward life, however, is on the contrary full of interests and of incidents of even a striking and exciting kind. The discovery of a fact which overthrows or remodels our ideas on a whole branch of science; the experimental proof of a general law hitherto unrecognised; the employment of a new and happy combination of known facts to effect an invention of general applicability and utility ; these are the peaceful victories of the man of science which may well be thought to outweigh the high-sounding achievements of the more public professions."

In the columns which follow the above will be found a statement of the chief experimental researches which have not only raised Bunsen by the common consent of all who can understand the results of accurate and farreaching methods to the highest point of scientific honour, but also of those more popular discoveries which have made his name a household word in circles far wider than those of purely scientific appreciation. Now, therefore, it is only necessary to recall the main facts of his life work ; to note, in the first place, that his desire to unravel the secrets of nature was unalloyed by any attempt to make capital out of any application of his discoveries. "To one man," he often said, "comes the duty of discovery, to another that of applying that discovery to practical uses." Like our great countryman Faraday, Bunsen consistently refused to be drawn away from the paths of purely scientific investigation, and, though too clear-sighted a mind to belittle the importance of the application of scientific discovery to every-day life, rightly judged that to him belonged the undoubtedly higher and nobler work of enlarging the boundaries of knowledge.

The next thing to be noted about Bunsen's work is its originality and its accuracy. It matters not whether we look into his purely chemical investigations, at his chemico-geological researches, or at those--perhaps the most remarkable amongst the many questions he answered - which lie on the borderland of physics and chemistry, in every case we rise from the study not merely feeling that we have to do with a master's mind and hand, but that each investigation is stamped by an original mode of treatment and by an accuracy of thought and of manipulative power which, it is not too much to say, has rarely if ever been equalled.

In no instance was this rare combination of mental and manual dexterity more strikingly shown than in his investigation of the compounds of cresium, the rarest of the two alkali metals which he discovered by means of spectrum analysis. In order to prepare the pure salts of this metal, some scores of tons (I write this away from books, and therefore cannot give the exact figures) of Dürkheim mineral water had to be evaporated, and from this residue it was only possible to obtain some five or six grams of the pure chloride. Nevertheless, from this comparatively minute quantity Bunsen succeeded not only in preparing and analysing all the important salts of cæsium, but in ascertaining by goniometric methods their exact crystalline form. So that he was able to supply all the information requisite to a complete understanding of the position of this new element and its compounds to those of its well-known relations potassium and sodium.

Then look at his gasometric methods. He was the first to attempt anything like exactitude in the measurement of 